\title{
College Adjustment of First Year Students: The Role of Social Anxiety
}

\author{
Ruseno Arjanggi (corresponding author) \\ Faculty of Psychology Universitas Islam Sultan Agung, Indonesia \\ ruseno@unissula.ac.id \\ Luh Putu S. Kusumaningsih \\ Faculty of Psychology Universitas Islam Sultan Agung, Indonesia
}

\begin{abstract}
This research aims to analyze the correlation between social anxiety and college adjustment. 436 undergraduate psychology students of five universities in Central Java were involved in this study. All respondents completed a questionnaire about student adjustment to college, and social anxiety scale. Canonical correlation was conducted to analyze the data. The result showed that fear of negative evaluation correlates with academic and personal-emotional adjustment, but not with social adjustment and institutional adjustment, while social avoidance and distress correlate with all of the dependent variables. This study suggests about the role of social anxiety to college adjustment. These findings investigate further discussion about appropriate intervention to address adjustment problems among college students.
\end{abstract}

Keywords: Academic adjustment, social adjustment, personal-emotional adjustment, institutional adjustment, social anxiety.

\section{Introduction}

Studying in higher education exposes students to a variety of new challenges including academic demands, autonomy toward their needs and activities, and more independent in learning than the previous education (Credé \& Niehorster, 2012). First year students need to master how to set up a new social environment, develop the orientation based on the institution in where they are admitted, become productive members of the community in their university, and adjust to new roles and responsibilities (Aderi, Jdaitawi, Ishak, \& Jdaitawi, 2013; Credé \& Niehorster, 2012; Kneipp, Kelly, \& Cyphers, 2009).

\section{The problem of college student adjustment}

However, first-year students will face the challenge of adjustment. They often find that the package of learning and teaching methods is different from those obtained from the secondary school level. Generally, learning in college has more challenge than high school. It provides more reading assignments, preparing articles and examination of articles through class presentations and quizzes to evaluate achieved competence. Lecturers expect them to do more work outside the classroom. In order to survive, they must take responsibility for their actions. This condition can lead them to emotional tension. In some cases, college students can use various kinds of assistance to solve the pressures of life and duties, such as smoking and alcohol consumption (Salami, 2011).

Successful college adjustment can be seen from their involvement in institutional activities, psychological wellbeing, and good academic performance (Julia \& Veni, 2012). 
The existence of new responsibilities could drive them to be doubt on their own ability in adjusting to their academic tasks and new cultures of their friends which then become pressure for them. Student adjustment will affect academic performance (Abdullah \& Elias, 2009). Adjustment problems happen to them because they are at the level of adolescent development. It is a period when they feel self-identity crisis, and meet demands of other development as an effect of new challenges such as being separated from their parents (Wiley \& Berman, 2013).

The adjustment process is the way in which individuals try to cope with stress, conflict, tension, and meet their needs (Julia \& Veni, 2012). During this process, the individual also seeks to maintain a harmonious relationship with the environment. In addition, adjustment is also defined as someone interaction with the environment(Abdullah \& Elias, 2009). Furthermore, adjustment to college demonstrates academic achievement and personal growth (Abdullah \& Elias, 2009). This approach means that students are able to make adjustment by having sufficient academic performance, passing all subjects, and meeting graduation time, while those who do not adjust to college well are characterized with the contrast criteria; their achievement is not satisfactory, marginal, failure, as well as the tendency to drop out. Besides academic achievement, adjustment to college also involves an element of personal growth in non-academic such as art and music, creativity, and leadership (Abdullah \& Elias, 2009).

Adjustment to college consists of four dimensions namely academic adjustment, social adjustment, adjustment of personal emotion, and institutional adjustments (Beyers \& Goossens, 2002; Marmarosh \& Markin, 2007; Taylor \& Pastor, 2007). Academic adjustment is how well students cope with the demands of education, such as motivation to complete academic requirements, academic effort and satisfaction with academic environment. Social adjustment includes student involvement in social activities, and satisfaction with the various aspects of lecture experience. Personal-emotional adjustment involves students prone to emotional problems, such as the manifestation of symptoms of depression. While the institutional adjustments describes students satisfaction with their lecture experience in the university where they present as a student (Salami, 2011).

\section{Social Anxiety and Adjustment to College}

Social anxiety is such a state of emotional distress characterized by fear and avoidance behavior in real social interactions (Puklek \& Vidmar, 2000). Students with social anxiety problems are at risk for social and emotional problems in the first half and dropped out in his second year (Nordstrom, Goguen, \& Hiester, 2014). Besides, social anxiety also triggers symptoms of depression that require intervention (Nordstrom et al., 2014).

Some of the problems that occur in the freshmen are anxiety, depression, loneliness, and withdraw from social interaction. Most first-year college students have symptoms of anxiety that affect their academic adjustment, which means that they may be vulnerable to these symptoms (Kneipp et al., 2009). During their first year, they have a challenging transition period, because it is a period of adjustment from dependence in fulfilling their needs, demands of academic and social relations towards independence (Arjanggi, 2013). Based on these problems, this study examines the effect of social anxiety on the adjustment to college student.

\section{Objective and Hypotheses}

The previous research with longitudinal measurement showed that self-esteem was a mediator of social anxiety and academic college adjustment (Nordstrom et al., 2014). The longitudinal measurement could impact 
internal validity. Therefore, the purpose of this study is to examine the role of fear of negative evaluation and social avoidance, and distress in measuring academic adjustment, social adjustment, personal and emotional adjustment and institutional adjustment. The hypothesis formulated in this study is that there is negative influence on the set I of variables covering fear of negative evaluation and social avoidance, and distress to the set II of variables including academic adjustment, social adjustment, personal-emotional adjustment, and institutional adjustment.

\section{Method \\ Participants}

The sample consisted of 436 college student (ranging from 18 to 19 years old). They were recruited from five universities in Central Java, Indonesia, who were registered in psychology in their first year. Only data from participants did complete all of the items of both scales. 93 of them are males while 343 are females.

\section{Instruments}

Student adjustment to college questionnaire was used and adapted to collect the data (Carter, Locks, \& Winkle-Wagner, 2013). Questionnaires measure student adjustment transition in college (Carter et al., 2013). This scale has been used in some previous studies (Beyers \& Goossens, 2002, 2003; Feldt, Graham, \& Dew, 2011; Taylor \& Pastor, 2007). Student adjustment to college consisted of four subscales namely academic adjustment, social adjustment, adjustment of personal emotion, and institutional adjustments (Beyers \& Goossens, 2002; Marmarosh \& Markin, 2007; Taylor \& Pastor, 2007). The questionnaire contains 66 items of Likert response format with 5 options. Favorable scoring item is with range 5 which is used to respond very fit and 1 for contrast, while the unfavorable is vice versa. The results of translating and testing each subscale obtained items that are reliable and satisfactory on each subscale including: academic adjustment $(\alpha=0.836)$, social adjustment ( $\alpha=0.759)$, personal emotion adjustment $(\alpha=0.719)$, and institutional adjustment $(\alpha=0.693)$.

Social anxiety scale was used to measure students' social anxiety whose scale is adapted from La Greca consisting of two subscales namely fear of negative evaluation and social avoidance, and distress (Garcia-Lopez et al., 2011; Nordstrom et al., 2014; Puklek \& Vidmar, 2000; Ranta, Junttila, Laakkonen, Uhmavaara, \& Greca, 2012). The scale contains 18 items with Likert-response format of 5 options. Favorable scoring item is with range 5 which is used to respond very fit and 1 for contrast. After the process of translating and analyzing the item was conducted, it was then known that the fear of negative evaluation subscale was appropriate to Cronbach Alpha coefficient $(\alpha=0.878)$ and social avoidance, and distress $(\alpha=0.842)$.

\section{Procedure}

The participants in this study were psychology students from five universities in Central Java who were selected by random cluster depending on the number of classes where each psychology faculty was grouped. Researchers made a range between 30\% -40\% of the overall number of students for each psychology faculty. Having collected the data of the candidates, the researcher conducted the next stage which was distributing the scale to the respondents. The fewest respondents were from Purwokerto because the number of their students isthe fewest among other cities. Among the 448scales, the 436 scales were filled completely and analyzed. 


\section{Result \\ Descriptive Statistics}

The results of descriptive statistical analysis showed that fear of negative evaluation mean the female subscale score (23.0583, $\mathrm{SD}=5.47958)$ was higher than the mean score $(22.1075, \mathrm{SD}=5.54127)$. Distress subscale mean score of male (27.1505, $\mathrm{SD}=5.75580)$ was higher than the mean score of female (26.9650, $\mathrm{SD}=5.64433)$. Academic adjustment subscale mean score of female (84.3965, $\mathrm{SD}=8.51831)$ was higher than the mean score of male (80.3871, $\mathrm{SD}=8.73403$ ). Social adjustment subscale mean score of male was 70.3226, with SD 6.38470 , while the mean score of female was 70.5569, with SD 6.52405. Personalemotional adjustment subscale mean score of male was 46.5484, withSD6.14944, while the mean score of female was 46.4548 , with SD 6.35984. Institutional adjustment subscale mean score of male was 26.6774, withSD3.59093, while the mean score of femalewas 27.8280, withSD3.30994. The results of descriptive statistical analysis are presented in table 1 (see appendix).

\section{Hypotheses Analysis}

The data were analyzed using canonical correlation to study two sets of data with two or more dependent variables (Bordens \& Abbott, 2011). Before presenting canonical correlation analysis, the results of significant multivariate were tested to see if canonical model is statistically significant or not. The author chose Wilks Lambda who tested the first canonical significance. The results showed significant multivariate test of Wilks $\lambda=0.72387, \mathrm{~F}(8,862.00)=18.89498, \mathrm{p}<0.05$, (table 2), soit can be concluded that the first canonical correlation is significant.

The model examined in this study covered two independent variables and four dependent variables. Canonical correlation value for the first canonical function was 0.47737 (Table 3), which showed that the amount of shared variants between the data sets of social anxiety and adjustment to college is $22788 \%$. The second canonical correlation indicates a maximum correlation between the two variables of canonic which was undiscovered by the first canonical function (Çetin, İlhan, \& Yilmaz, 2014). The value of the second canonical function was 0.24999 , indicating that the number of shared variance between two sets of data in the second function was $6,249 \%$.

Table 4 presents the data set analysis of variables including social anxiety, and adjustment to college, including their dimensional reduction. It also shows a model of canonic consisting of the values of the cumulative of the two functions of canonic obtained from the analysis of the function ( 1 to 2) which was statistically significant [Wilk's $\lambda$ $=0.72387, \mathrm{~F}(8,862.00)=18.89498, \mathrm{p} 0.001]$.

There was asignificant correlation between the data sets of social anxiety and adjustment to college on their both canonic function (function 2 to 2) after the first canonic function was calculated in a way that would maximize the correlation between variables where canonic was included in the evaluation [Wilk's $\lambda=0.93751, \mathrm{~F}(3,432.00)=9.59890$, $\mathrm{p}$ 0:01] therefore, both of them could be analyzed further.

The measurement of canonical variants can be expressed in canonical or canonical loading weight (Table5). From the function1on the dependent variables, it could be known that there was a correlation figure $\geq 0.5$ namely personal-emotional adjustment with correlation value of 0.72948 .

The function 1 of the dependent variables obtained four canonical loading number $\geq 0$. 5 namely academic adjustment which had canonical loading value of 0.54904 , social adjustment to canonical loading resulting 0.73442 , personal-emotional adjustment has 
loading was 0.88309 , and institutional adjustment to the canonical loading resulting 0.54106 (See table 6).

Based on the results of canonical or canonical weight, it is known that there was a significant correlation between the dependent variables and independent variables, it could be seen from the covariate values which resulted $>0.5$ on fear of negative evaluation with canonical value of -0.821 , and social avoidance and distress resulted canonical value of -0.959 (see table 7). The negative signs on the fear of negative evaluation and social avoidance and distress showed the correlation direction among the two variables independent and the four dependent variables.

The next step is to see the results of regression analysis by looking at the t-value and significance values of each independent variable in controlling or affecting the dependent variables. The effect of fear of negative evaluation (X1) on academic adjustment (Y1) obtained $\mathrm{t}$ value $=-2.47078$, with significant level of 0.014 (p 0.05), which means that both of them had an effect on academic adjustment. The data also resulted that social avoidance and distress (X2) on academic adjustment (Y1) obtained t-value of -2.48024 , with significant level of 0.014 ( $p$ 0.05 ), which means that both independent variables had an effect on academic adjustment. Fear of negative evaluation (X1) does not have an effect on social adjustment (Y2) with t-value $=0.94929$, with significant level of 0343 ( $>>0.05)$, while social avoidance and distress (X2) had an effect on social adjustment (Y2) which was shown from the $\mathrm{t}$-value $=-7.21668$, with significant level of $0.000(p<0.05)$. There was an effect of fear of negative evaluation (X1) on personalemotional adjustment (Y3) which was shown from the $\mathrm{t}$-value $=-5.24548$, with significant level of $0.000(p<0.05)$. In addition, there was also an effect of social avoidance and distress (X2) on personal-emotional adjustment (Y3) which was shown from $\mathrm{t}$-value $=-3.43006$, with significant level of $0.001(\mathrm{p}<0.05)$. Furthermore, There was no effect of fear of negative evaluation(X1) on institutional adjustment (Y4) which was shown from the tvalue $=-0.72800$, with significant level of $0.467(\mathrm{p}>0.05)$. All in all, there was no effect of social avoidance and distress (X2) on institutional adjustment (Y4) which was shown from the $\mathrm{t}$-value $=-3.89906$, with significant level of $0.000(\mathrm{p}<0.05)$.

\section{Discussion}

The result of this study showed that there was negative correlation among the variables of fear of negative evaluation, academic adjustment and personal-emotional adjustment. This means that the lower fear of negatif evaluation, the better academic adjustment and institutional adjustment of students, while the higher fear of negatif evaluation the lower academic adjustment and personal-emotional adjustment. It can be concluded that those who have high fear of negative evaluation will affect their ability in adjusting to academic demands and general psychological distress, as the previous study resulting that social anxiety has an effect on academic performance (Brook \& Willoughby, 2015; Strahan, 2003) and anxiety sensitivity has an effect on psychological distress (Allan, Norr, Capron, \& Schmidt, 2015) which manifests personal-emotional adjustment (Beyers \& Goossens, 2003).

However, fear of negative evaluation has no correlation with social adjustment and institutional adjustment. This finding is not in line with the previous study which stated that social anxiety has an effect on all area of adjustment to college (Nordstrom et al., 2014). This finding indicated that fear of negative evaluation cannot explain its effect on student interpersonal experiences in campus life, and has no effect on their commitment to their campus. 
Social avoidance and distress have negative correlation with academic adjustment, social adjustment, personal-emotional adjustment and institutional adjustment. This means that the lower the level of social avoidance and distress the better the level of academic adjustment, social adjustment, personalemotional adjustment and institutional adjustment. This finding is in line with the previous study which claimed that all of social anxiety affects adjustment to college (Nordstrom et al., 2014).

Social avoidance and distress are avoidance towards social situation and meeting new friends that will lead to social distress and uncomfortable feeling in someone's life (Beyers \& Goossens, 2002). Those who are indicated to have social avoidance and distress will get difficult in adjusting to academic tasks, because they are difficult in networking in order to get information about campus life (Beyers \& Goossens, 2003). Those with low social anxiety will be close to their colleague where this leads to the improvement of adjustment (Marmarosh \& Markin, 2007). This is because that it will increase sense of security during their first year adjustment process (Marmarosh \& Markin, 2007).

The adjustment to campus life requires skill to interact with new friends and situation of their previous education.It is an indication of high social anxiety that they avoid extra or intracurricular activities in campus, and this indicates low social adjustment (Beyers \& Goossens, 2002). In addition, high social anxiety can also be indicated from taskmisinterpretation given by their lecturers, that indicates academic adjustment (Beyers \& Goossens, 2002), caused by lack of information network which includes the indicator of social adjustment (Beyers \& Goossens, 2002).

\section{Conclusion}

Student ability in adjustment to college is affected by social anxiety. The result shows that an appropriate intervention is necesery to tackle student distress during their first year. This study provides recommendations to institutions of higher education in order to prepare fortheir studentduring the orientation of campus life, academic tasks, and how to get along with faculty and fellow college student. Through proper orientation, their process of adjustment to college will be accelerated.

Fear of negative evaluation has an effect on academic adjustment and emotional-personal adjustment, but has not social adjustment and institutional adjustment. Social avoidance and distress have an effect on academic adjustment, social adjustment, social adjustment, personal-emotional adjustment and institutional adjustment.

All in all, it is hoped to conduct further research to examine several variables that are not included in this study such as a pattern of ethnic identification, a source of social support, psychologically self-reliance, gender, and parenting.

\section{Acknowledgement}

This research was funded by Indonesian Ministry of Research, Technology, and Higher Education in 2015. 


\section{References}

Abdullah, M. C., \& Elias, H. (2009). Adjustment amongst first year students in a Malaysian. European Kournal of Social Sciences, 8(3), 496-505.

Aderi, M., Jdaitawi, M., Ishak, N. A., \& Jdaitawi, F. (2013). The influence of demographic variables on university students' adjustment in North Jordan. International Education Studies, 6(2), 172178. http://doi.org/10.5539/ies.v6n2p172

Allan, N. P., Norr, A. M., Capron, D. W., \& Schmidt, N. B. (2015). Specific Associations between Anxiety Sensitivity Dimensions and Fear and Distress Dimensions of Emotional Distress Disorders. Journal of Psychopathology and Behavioral Assessment, 37(1), 67-78. http://doi.org/10.1007/s10862-014-9437-y

Arjanggi, R. (2013). The Exploration study about college adjustment of freshman. In International Conference on Psychology in Health, Educational, Social, and Organizational Setting (pp. 183189). Surabaya: Unair Press.

Beyers, W., \& Goossens, L. (2002). Concurrent and predictive validity of the student adaptation to college questionnaire in a sample of european freshman students. Educational and Psychological Measurement, 62(3), 527-538.

Beyers, W., \& Goossens, L. (2003). Psychological separation and adjustment to university: moderating effect of gender, age, and perceived parenting style. Journal of Adolescent Research, 18(4), 363-382. http://doi.org/10.1177/0743558403253812

Bordens, K., \& Abbott, B. (2011). Research design and methods: A process approach .Pediatric Hematology-Oncology. Retrieved from http://informahealthcare.com/doi/abs/10.1080/08880010290057291 \nhttp://psycnet.apa.org/psy cinfo/2001-18329-000

Brook, C. A., \& Willoughby, T. (2015). The social ties that bind: social anxiety and academic achievement across the university years. Journal of Youth and Adolescence, 44(5), 1139-1152. http://doi.org/10.1007/s10964-015-0262-8

Carter, D. F., Locks, A. M., \& Winkle-Wagner, R. (2013). From when and where I enter: theoritical and empirical consideration of minority students' transition to college. In M. B. Paulsen (Ed.), Haigher Education: Handbook of Theory and Research; Volume 28 (p. 782). London: Springer. Retrieved from http://books.google.com/books?id=WbZGAAAAQBAJ\&pgis=1

Çetin, B., İlhan, M., \& Yilmaz, F. (2014). An investigation of the relationship between the fear of receiving negative criticism and of taking academic risk through canonical correlation analysis. Educational Sciences: Theory \& Practice, 14(1), 146-159. http://doi.org/10.12738/estp.2014.1.1616

Credé, M., \& Niehorster, S. (2012). Adjustment to college as Measured by the Student Adaptation to College Questionnaire: A Quantitative Review of its Structure and Relationships with Correlates and Consequences. Educational Psychology Review, 24(1), 133-165. http://doi.org/10.1007/s10648-011-9184-5

Feldt, R. C., Graham, M., \& Dew, D. (2011). Measuring Adjustment to College: Construct Validity of the Student Adaptation to College Questionnaire. Measurement and Evaluation in Counseling and Development, 44(2), 92-104. http://doi.org/10.1177/0748175611400291

Garcia-Lopez, L. J., Ingles, C. J., Garcia-Fernandez, J. M., Hidalgo, M. D., Bermejo, R., \& Levpuscek, M. P. (2011). Psychometric Properties and Clinical Cut-Off Scores of the spanish 
version of the social anxiety scale for adolescents. Jounal of Personality Assessment, 93(5), 474-482. http://doi.org/10.1080/00223891.2011.594126

Julia, M., \& Veni, B. (2012). An Analysis of the Factors Affecting Students' Adjustment at a University in Zimbabwe. International Education Studies, 5(6), 244-251. http://doi.org/10.5539/ies.v5n6p244

Kneipp, L. B., Kelly, K. E., \& Cyphers, B. (2009). Feeling at Peace with College : Religiosity, Spiritual Well-Being, and College Adjustment. Individual Differences Research, 7(3), 188196.

Marmarosh, C. L., \& Markin, R. D. (2007). Group and personal attachments: Two is better than one when predicting college adjustment. Group Dynamics: Theory, Research, and Practice, 11(3), 153-164. http://doi.org/10.1037/1089-2699.11.3.153

Nordstrom, A. H., Goguen, L. M. S., \& Hiester, M. (2014). The Effect of Social Anxiety and SelfEsteem on College Adjustment, Academics, and Retention. Journal of College Counseling, 17(April), 48-64. http://doi.org/10.1002/j.2161-1882.2014.00047.x

Puklek, M., \& Vidmar, G. (2000). Social anxiety in Slovene adolescents: Psychometric properties of a new measure, age differences and relations with self-consciousness and perceived incompetence. European Review of Applied Psychology, 50(2), 249-258. Retrieved from http://ibmi.mf.uni-lj.si/ibmi/biostat-center/predtiski/ERAP_Puklek_Vidmar.pdf

Ranta, K., Junttila, N., Laakkonen, E., Uhmavaara, A., \& Greca, A. M. La. (2012). Social Anxiety Scale for Adolescents ( SAS-A ): Measuring social anxiety among Finnish adolescent. Child Psychiatry \& Human Development, 43(February), 574-591. http://doi.org/10.1007/s10578-0120285-2

Salami, S. O. (2011). Psychosocial Predictors of Adjustment Among First Year College of Education Students. US-China Education Review, 8(2), 239-248.

Strahan, E. Y. (2003). The effects of social anxiety and social skills on academic performance. Personality and Individual Differences, 34, 347-366.

Taylor, M. a., \& Pastor, D. a. (2007). A Confirmatory Factor Analysis of the Student Adaptation to College Questionnaire. Educational and Psychological Measurement, 67(6), 1002-1018. http://doi.org/10.1177/0013164406299125

Wiley, R. E., \& Berman, S. L. (2013). Adolescent identity development and distress in a clinical sample. Journal of Clinical Psychology, 69(12), 1299-304. http://doi.org/10.1002/jclp.22004 
Journal of Educational, Health and Community Psychology

Vol 5, No 1, 2016

Ruseno Arjanggi, S Kusumaningsih

\section{Apenddix}

Table 1

Descriptive Statistics

\begin{tabular}{lllllll}
\hline Variables & Sex & N & Min & Max & Mean & SD \\
\hline Fear of negative evaluation & Male & 93 & 8 & 39 & 22.1075 & 5.54127 \\
& Female & 343 & 8 & 40 & 23.0583 & 5.47958 \\
Social avoidance and distress & Male & 93 & 10 & 37 & 27.1505 & 5.75580 \\
& Female & 343 & 12 & 48 & 26.9650 & 5.64433 \\
Academic adjustment & Male & 93 & 64 & 103 & 80.3871 & 8.73403 \\
& Female & 343 & 59 & 111 & 84.3965 & 8.51831 \\
Social adjustment & Male & 93 & 52 & 84 & 70.3226 & 6.38470 \\
\multirow{3}{*}{ Personal-emotional adjustment } & Female & 343 & 52 & 88 & 70.5569 & 6.52405 \\
& Male & 93 & 29 & 62 & 46.5484 & 6.14944 \\
Institutional adjustment & Female & 343 & 26 & 64 & 46.4548 & 6.35984 \\
& Male & 93 & 15 & 35 & 26.6774 & 3.59093 \\
& Female & 343 & 14 & 35 & 27.8280 & 3.30994 \\
\hline
\end{tabular}

Table 2

Multivariate Test of Significant

\begin{tabular}{llllll}
\hline Test name & Value & Approx. F & Hypoth. DF & Error DF & Sig. of F \\
\hline Pillais & 0.29037 & 18.34345 & 8.00 & 864.00 & 0.000 \\
Hotellings & 0.36180 & 19.44655 & 8.00 & 860.00 & 0.000 \\
Wilks & 0.72387 & 18.89498 & 8.00 & 862.00 & 0.000 \\
Roys & 0.22788 & & & & \\
\hline
\end{tabular}

Table 3

Eigenvalues and Canonical Correlation

\begin{tabular}{llllll}
\hline Root No. & Eigenvalue & Percentage & $\begin{array}{l}\text { Cumulative } \\
\text { percentage }\end{array}$ & $\begin{array}{l}\text { Canonical } \\
\text { correlation }\end{array}$ & $\begin{array}{l}\text { Squared Canonical } \\
\text { correlation }\end{array}$ \\
\hline 1 & 0.29514 & 81.57554 & 81.57554 & 0.47737 & 0.22788 \\
2 & 0.06666 & 18.42446 & 100.00000 & 0.24999 & 0.06249 \\
\hline
\end{tabular}


Journal of Educational, Health and Community Psychology

Vol 5, No 1, 2016

Ruseno Arjanggi, S Kusumaningsih

Table 4

Dimensionality Reduction Analysis

\begin{tabular}{llllll}
\hline Roots & Wilk's L. & F & $\begin{array}{l}\text { Hypothesis } \\
\text { DF }\end{array}$ & Error DF & $\begin{array}{l}\text { Significance } \\
\text { Value of F }\end{array}$ \\
\hline 1 to 2 & 0.72387 & 18.89498 & 8.00 & 862.00 & 0.000 \\
2 to 2 & 0.93751 & 9.59890 & 3.00 & 432.00 & 0.000 \\
\hline
\end{tabular}

Table 5

Standardized Canonical Coefficientsof Dependent Variables

\begin{tabular}{lll}
\hline \multirow{2}{*}{ Subscale } & \multicolumn{2}{c}{ Function No. } \\
\cline { 2 - 3 } & 1 & 2 \\
\hline Academic adjustment & -0.14391 & 0.50318 \\
Social adjustment & 0.47617 & -1.05879 \\
Personal-emotional adjustment & 0.72948 & 0.62106 \\
Institutional adjustment & 0.15728 & -0.08709 \\
\hline
\end{tabular}

Table 6

The Correlation between Dependent and Canonical Variables

\begin{tabular}{lll}
\hline \multirow{2}{*}{ Subscale } & \multicolumn{2}{c}{ Function No. } \\
\cline { 2 - 3 } & 1 & 2 \\
\hline Academic adjustment & 0.54904 & 0.16983 \\
Social adjustment & 0.73442 & -0.58599 \\
Personal-emotional adjustment & 0.88309 & 0.45088 \\
Institutional adjustment & 0.54106 & -0.16170 \\
\hline
\end{tabular}

Table 7

Correlation between Covariates and Canonical Variables

\begin{tabular}{lll}
\hline \multirow{2}{*}{ Subscale } & \multicolumn{2}{c}{ Canonical Variables } \\
\cline { 2 - 3 } & 1 & 2 \\
\hline Fear of negative evaluation & -0.82100 & -0.57093 \\
Social avoidance and distress & -0.95977 & 0.28080 \\
\hline
\end{tabular}

